\title{
Os CEUs da Prefeitura de São Paulo: comunicação no espaço de inclusão social
}

Cristiane Hyppolito

Publicitária, especialista em Gestão da Comunicação. Assessora no setor de Projetos Especiais da Secretaria Municipal de Educação de São Paulo.

E-mail: chyppolito@uol.com.br

Os Centros Educacionais Unificados (CEUs) da Prefeitura de São Paulo, administrados pela Secretaria Municipal de Educação, são equipamentos públicos que oferecem espaços para o desenvolvimento de atividades esportivas, de lazer, entretenimento e cultura - tudo isso em um ambiente educacional.

Resultam de uma proposta político-pedagógica estabelecida no fortalecimento da escola pública, articulada ao desenvolvimento comunitário. Porém, a comunicação entre os CEUs e as comunidades do seu entorno não é eficiente, assim como não existem processos de comunicação interna sistematizados. Tal problema é o tema de nossa pesquisa, desenvolvida no Curso de Gestão da Comunicação da Escola de Comunicações e Artes da Universidade de São Paulo. Procuramos analisar o impacto e as mudanças ocorridos com a introdução desse equipamento em áreas periféricas da cidade, a adaptação e integração da comunidade do entorno e a capacidade de o projeto de Gestão em Comunicação estabelecer um canal de comunicação entre suas várias instâncias. Buscamos embasamento em outras experiências de utilização de espaços públicos de educação e nas teorias acerca do tema produzidas por educadores e pesquisadores para, a partir daí, propormos um projeto de intervenção que contemplasse as diferenças entre os núcleos sociais, seus códigos e suas demandas locais.

\section{CONCEPÇÃO}

Nos anos 1950, Anísio Teixeira ${ }^{1}$ dizia que a escola deveria ser pública, laica e obrigatória. Além de em tempo integral para professores e alunos, ela tinha de ser também municipalizada, para atender aos interesses de cada comunidade. Nessa época idealizou em Salvador, Bahia, o Centro Educacional Carneiro Ribeiro, mais conhecido como Escola Parque ${ }^{2}$, que, com outros projetos da mesma

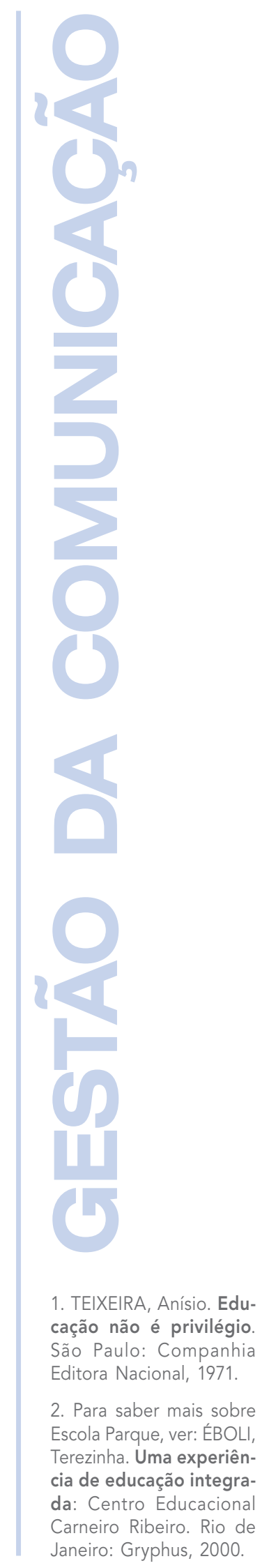


natureza, inspiraram a retomada de uma proposta de espaço educativo global para a população mais pobre. Assim, a prefeita Marta Suplicy, em sua gestão (2001-2004), criou os Centros Educacionais Unificados, sendo inaugurada a primeira unidade, CEU Jambeiro, na Zona Leste, no dia 1ํ de agosto de 2003, e instaladas mais 20 unidades até o final de 2004, todas localizadas em áreas de periferia e com baixo Índice de Desenvolvimento Humano (IDH) ${ }^{3}$.

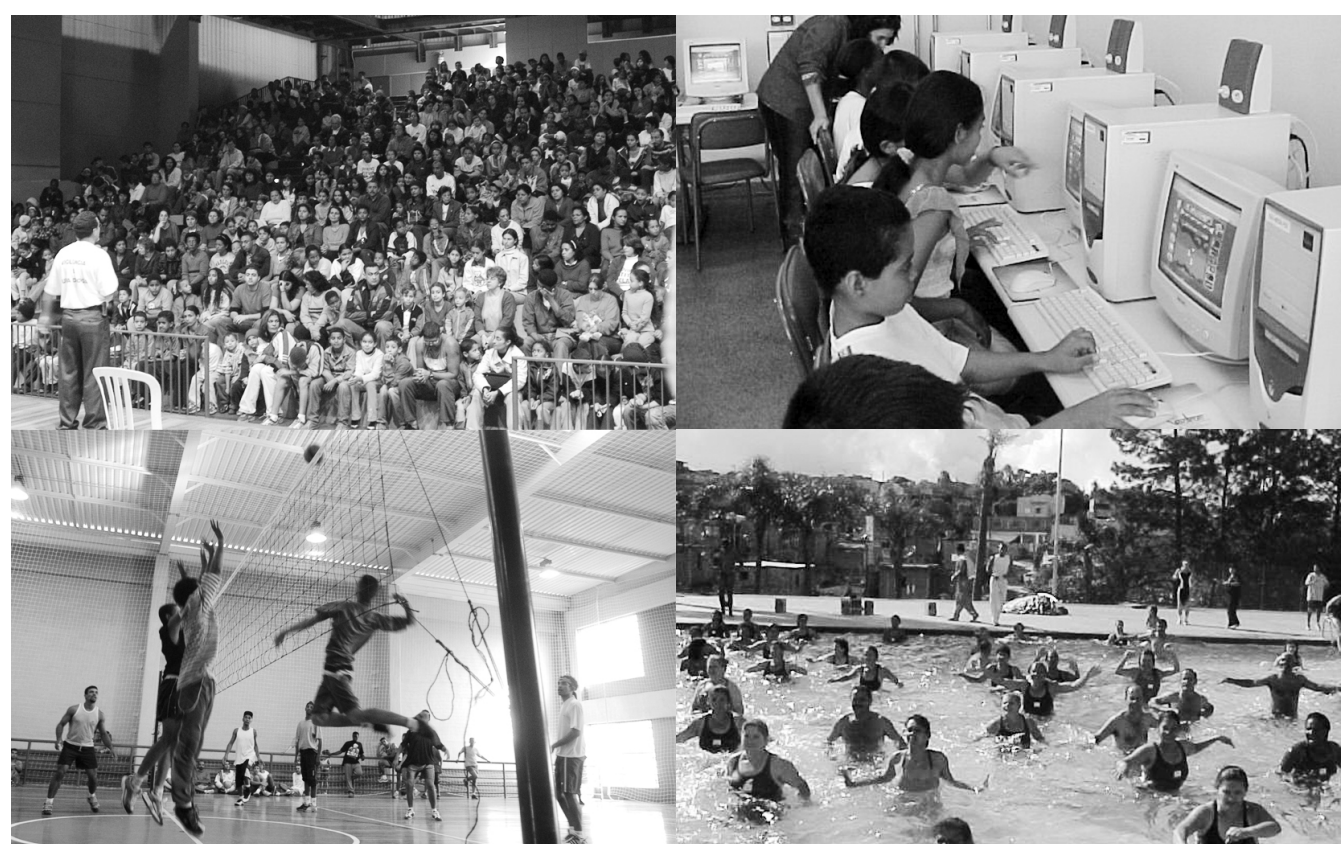

A integração social no espaço público e a minimização da segregação do espaço urbano. Fortalecimento da construção da cidadania.

3. O Índice de Desenvolvimento Humano é uma medida comparativa de fatores que utiliza como critérios indicadores de educação, longevidade e renda, para os diversos países do mundo. É uma maneira padronizada de avaliação e medida do bem-estar de uma população, especialmente do bem-estar infantil.
Construídos em terrenos com $13.000 \mathrm{~m}^{2}$, em média, os CEUs abrigam o Bloco Cultural, constituído de: teatro/cinema, biblioteca, salas multiuso e telecentro (salas com computadores conectados à internet para uso da comunidade); o Bloco Esportivo, com quadras, pista de skate e piscinas; e o Bloco Didático, composto de um Centro de Educação Infantil (CEI), uma Escola Municipal de Educação Infantil (EMEI) e uma Escola Municipal de Ensino Fundamental (EMEF), que também oferece Ensino para Jovens e Adultos (EJA).

Em 2007 a administração do prefeito Gilberto Kassab colocou em funcionamento quatro novos CEUs e outros estão em construção para serem entregues até o final de 2008.

\section{CENÁRIO URBANO}

A cidade de São Paulo é o retrato da desigualdade social. O maior centro econômico do país é cercado por bairros que não oferecem condições básicas de infra-estrutura, nem disponibilidade de equipamentos públicos, segurança, educação e saúde aos seus habitantes. Essa heterogeneidade, disposta geograficamente, gera o fenômeno chamado de segregação espacial, em que a diferen- 
ciação entre os bairros periféricos e a região central determina a manutenção dos índices de marginalidade social e a desintegração comunitária.

A integração social no espaço público tende a minimizar a segregação do espaço urbano, fortalecendo a construção da cidadania. Tratar os processos de comunicação numa dimensão horizontal, que contemple a diversidade cultural e étnica, pode propiciar a apropriação dos CEUs e das atividades nele oferecidas. Nesse sentido, as ações desenvolvidas devem ser construídas balizadas pelo conhecimento acumulado na experiência vivida por essas comunidades, acrescidas dos conhecimentos teóricos dos educadores, provocando a interlocução das diferentes culturas.

Recorremos a Jesús Martín-Barbero ${ }^{4}$ para afirmar que a elaboração da cultura popular acontece durante o processo de recepção, reconhecimento e apropriação. As competências culturais são as mediações que devemos considerar; desse modo, a comunicação pode ser o meio e, também, o efeito para o desenvolvimento dos cidadãos. A ênfase na informação local, a democratização do acesso aos meios de comunicação, a valorização da comunidade e o uso das novas tecnologias podem trazer resultados efetivos dentro de um processo colaborativo.

\section{UNIVERSO DA PESQUISA}

A pesquisa realizada teve como objetivo geral fazer um levantamento, com a população usuária, a equipe gestora e os funcionários dos CEUs, de sua percepção e avaliação sobre a experiência socioeconômica lá desenvolvida. Vale ressaltar que, no processo de reconstrução empírica da realidade, é necessário proceder à ruptura epistemológica entre o objeto científico e o objeto teórico. Como afirma Lopes, "o importante não é o que se vê, mas o que se vê com método, pois o investigador pode ver muito e identificar pouco e pode ver apenas o que confirma suas concepções"5. Para tanto, adotamos um método científico de pesquisa de campo baseado na análise de documentos disponíveis, entrevistas em profundidade e análise da comunicação, o que nos permitiu conhecer a realidade dos CEUs e balizar o projeto de intervenção proposto. Ademais, procuramos conhecer a cultura das comunidades usuárias em sua diversidade, referendada pelos significados de seu universo específico e não balizada por conceitos externos, mantendo - tanto quanto possível - um olhar sem valores preconcebidos.

\section{UNIDADES SELECIONADAS}

No presente trabalho adotamos como parâmetros para estudo três unidades:

- CEU Butantã - Situado no extremo oeste de São Paulo, com quase 350 mil habitantes, tornam-se evidentes as diferenças sociais que habitam o entorno: de um lado, as favelas Dona Amélia e do Sapé; do outro, o Caxingui, os novos residenciais do Jardim Bonfiglioli e, um pouco mais distante, as mansões do Jardim Guedala e do Morumbi.
4. MARTÍN-BARBERO Jesús. De los medios a las mediaciones: comunicación, cultura y hegemonía. México: Editoria Gustavo Gili, 1987. [Ed. bras.: Dos meios às mediações: comunicação cultura e hegemonia. 2. ed. Rio de Janeiro: Editora UFRJ, 2001.]

5. LOPES, Maria Immacolata Vassallo de. Pesquisa em comunicação. 8. ed. São Paulo: Loyola, 2005. p. 143 


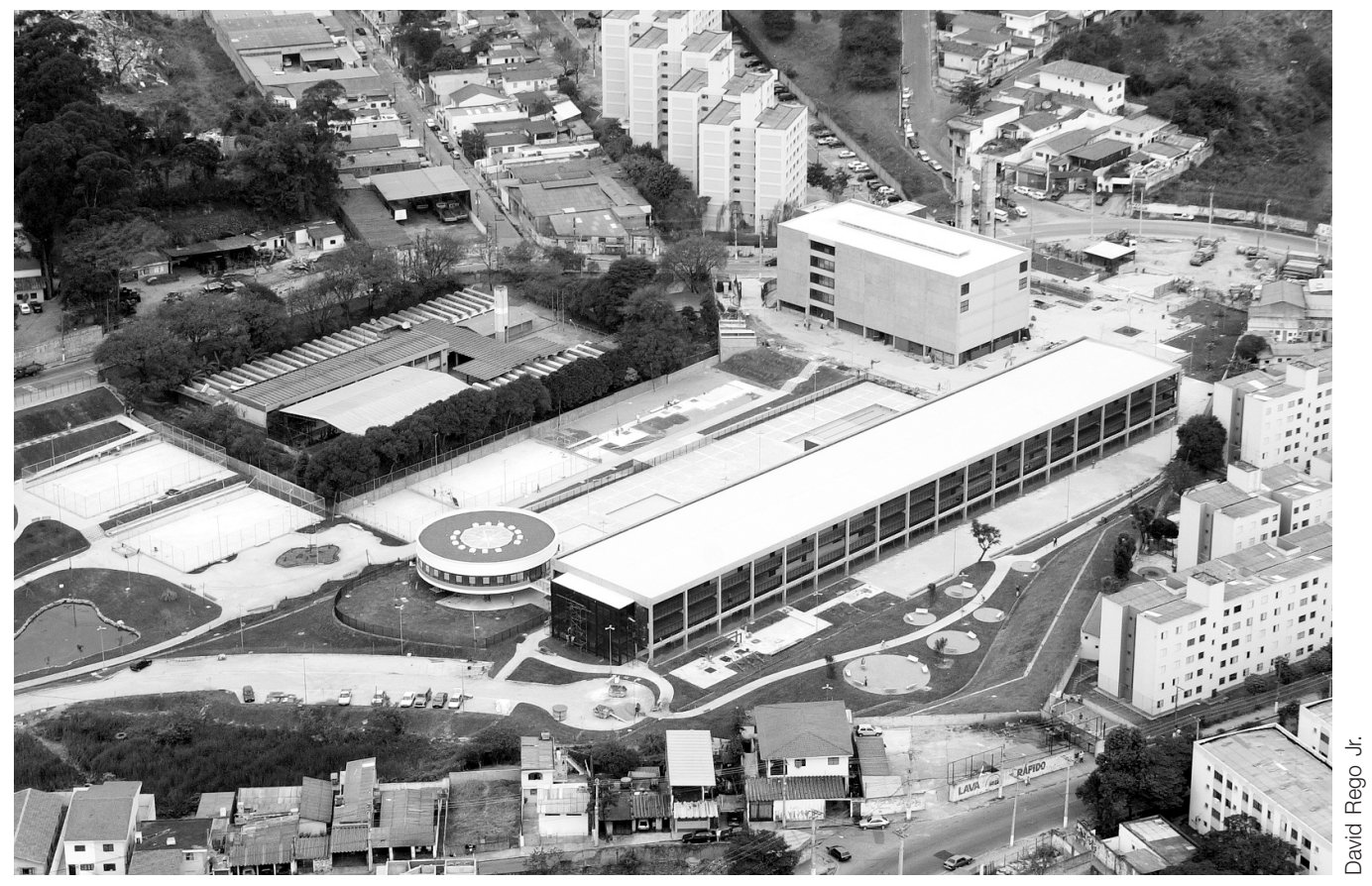

CEU Butantã.

- CEU São Mateus - a região, que possui cerca de 382 mil habitantes, está numa área de invasão, mais tarde adquirida pela prefeitura - na gestão de Luíza Erundina - e distribuída à população carente para que ali se fizessem conjuntos habitacionais em regime de mutirão. Fazem parte dessa área o Jardim Conquista, Parque da Boa Esperança e Jardim Augusta Helena.

- CEU Meninos - localizado na divisa da cidade de São Paulo com São Caetano do Sul, a portaria principal está voltada para o lado em que existem prédios e casas de classe média. Na parte posterior do CEU está a favela de Heliópolis, porém não existe uma entrada nesse lado, o que faz com que os moradores tenham de andar muito para acessar o equipamento. O complexo Heliópolis/São João Clímaco possui 1 milhão de $\mathrm{m}^{2}$, com uma população de cerca de 120 mil habitantes. É considerada a maior favela de São Paulo e a segunda maior do Brasil e da América Latina ${ }^{6}$.

6. Disponível em: <http:// www.unas.org.br/quem_ somos.html>. Acesso em: 20 maio 2007. 


\section{Os CEUs da Prefeitura de São Paulo • Cristiane Hyppolito}

No segundo grupo, entrevistamos os coordenadores de núcleo de ação cultural das três unidades de referência, tratando dos seguintes assuntos: divulgação dos eventos e atividades, informações gerais, eventos e projetos locais, recursos materiais e comunicação com a SME, coordenadorias e escolas do entorno.

Para registrar a visão da equipe gestora, participamos - como ouvintes - de duas reuniões (dinâmicas de grupo), ocorridas na SME com os gestores de todos os CEUs, nas quais se enfocaram temas administrativos, de concepção e uso do espaço, do papel do gestor no CEU, do relacionamento com as Unidades Escolares e de participação da comunidade.

\section{Seleção por disponibilidade}

Com relação à população usuária, realizamos uma visita em cada uma das três unidades, sempre aos finais de semana, quando procuramos ouvir as pessoas que estavam participando de alguma atividade e convidá-las a gravar uma entrevista. Essas entrevistas foram semidirigidas, seguindo um roteiro construído de forma empírica com base na referência teórica e no estudo documental realizado previamente.

\section{Análise da comunicação}

A comunicação nos CEUs é complexa, envolvendo vários níveis no seu âmbito interno e externo. Não existe na estrutura da SME uma área de comunicação organizada. Os vários setores que, de alguma forma, atuam no campo da comunicação não estão nem sequer ligados entre si e não apresentam unificação nos trabalhos desenvolvidos. Os CEUs também não dispõem de departamento de comunicação.

\section{PROPOSTA DE INTERVENÇÃO}

Entendemos que é imperativa a construção de processos de comunicação internos e externos e propomos um projeto amparado pelo gestor de comunicação que deverá conceber e contextualizar o problema, projetando uma forma de intervenção em termos comunicacionais.

Retornemos, então, ao problema: a comunicação entre o CEU e as comunidades do seu entorno não é eficiente, assim como não existem processos de comunicação interna sistematizados. Podemos afirmar, no entanto, que as possibilidades e meios para a intervenção são férteis e, seguramente, poderão atingir seu objetivo principal: maximizar a utilização dos equipamentos, trazendo para o interior dos CEUs a população do entorno, para que dele façam uso e se apropriem de maneira a dar ao projeto o verdadeiro sentido de inclusão social.

Concluímos, ao analisar os dados de nossa pesquisa, que alguns fatores devem ser problematizados por se tratarem de premissas a ser consideradas em nosso 
projeto de intervenção. O primeiro deles se refere ao público que visamos atingir. $\mathrm{O}$ que chamamos de comunidade do entorno não diz respeito a um grupo determinado e organizado, mas aos cidadãos que habitam aquela região, com áreas de interesse e/ou necessidades em comum, seja pela sua localização geográfica, seja por suas demandas sociais. Devemos, ainda, estender nosso foco àqueles que não são usuários. Torná-los usuários ou, pelo menos, sabedores dos processos em andamento nas unidades é parte importante do projeto que ora propomos.

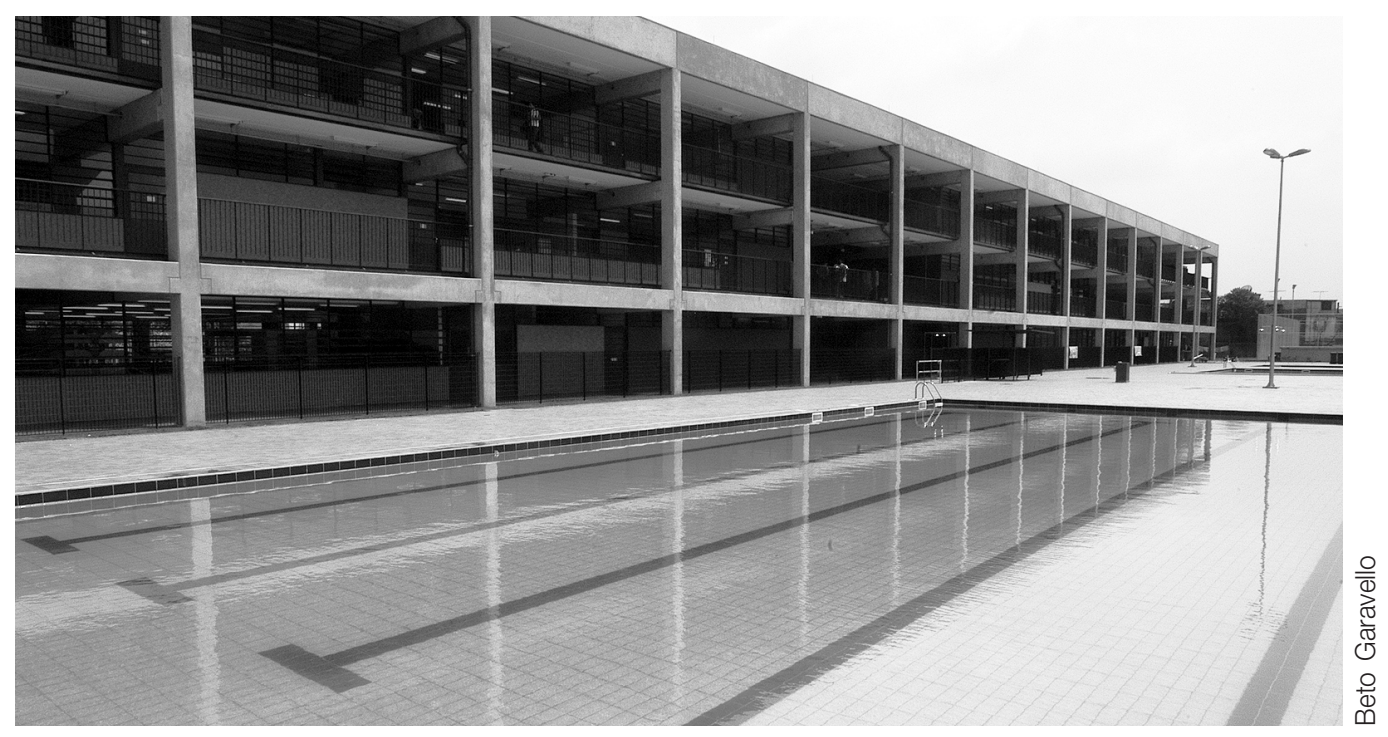

Uma das propostas da intervenção é maximizar a utilização dos equipamentos, trazendo para o interior dos CEUs a população que deles faça uso e se aproprie de maneira a dar ao projeto o verdadeiro sentido de inclusão social.

Outro fator é o impacto físico que a enorme construção dos CEUs constitui nos locais onde foram instalados. A arquitetura, a programação e os equipamentos representaram uma mudança física e conceitual. Percebemos que muitas pessoas, acostumadas à exclusão, evitam a integração, ou pior, nem sabem que têm direito àqueles equipamentos lá dispostos. Se hoje esse distanciamento não é raro nos 21 CEUs existentes, é imprescindível que o projeto de intervenção contemple mecanismos de divulgação em locais onde serão instaladas novas unidades, para que, quando de sua abertura, já se tenha iniciado o processo de integração com a comunidade.

O terceiro fator que destacamos é acerca da linguagem. Para assegurarmos uma comunicação eficiente devemos considerar a universalização de sua forma por meio de uma linguagem simples, de fácil entendimento e compreensão. Precisamos acrescentar, ainda, as peculiaridades de cada região, o perfil de seus moradores e as necessidades mais prementes encontradas nesses locais.

Por fim, entendemos que os processos comunicativos dos CEUs não podem estar sustentados no paradigma hegemônico, no qual o processo de comunicação se reduz à transmissão de informação. Pretendemos construir um projeto de intervenção plural, que contemple os diferentes modos de produção, apropriação e decodificação cultural, no uso social da comunicação. 
Os desafios e dificuldades são de toda ordem. Perpassam as condições de vida fincadas na desigualdade social, nos valores culturais, nos interesses públicos, etc. Mas, experiências concretas de participação popular na comunicação comunitária que, aliás, pode usar também os meios massivos, demonstram sua importância no processo de conquista da cidadania ajudando o homem a tornar-se sujeito ${ }^{7}$.

\section{PROJETO}

Procuramos desenvolver o projeto de intervenção levando em consideração o cenário global e as especificidades de cada CEU. A seguir, as etapas elaborativas e como pode se dar o processo de execução.

\section{Radiografia}

Detalhar dois quadros de características que nos dêem a real imagem do projeto. No primeiro quadro, devemos assinalar as características comuns a todas as unidades instaladas e em instalação. Equipamentos disponíveis, atividades, níveis de ocupação, necessidades estruturais, relacionamento com usuários, demandas técnicas etc. No segundo, informações específicas de cada região. Perfil de moradores, potenciais usuários, usuários efetivos, produção cultural - se há e qual é -, códigos de convivência, grau de periculosidade do entorno, existência de tráfico etc.

\section{Condução do processo}

Envolver a comunidade em todas as fases do processo estimula o sentimento de propriedade e confere maior possibilidade de êxito à sua implementação. Nessa visão, a criação de grupos de ressonância como forma de aferir a correção da coleta de dados e, num segundo momento, medir o grau de satisfação e de envolvimento dos usuários, é forma providencial de comprovar resultados e corrigir falhas de concepção e execução. O trabalho deverá ser desenvolvido e coordenado pelo gestor de comunicação, contando com uma equipe de colaboradores que participarão tanto da concepção como da instalação do projeto.

\section{Divulgação}

Detectar as redes de comunicação informais, reforçar a divulgação oral, trabalhar não somente com as lideranças instituídas, mas com a dona-de-casa, os comerciantes, e fortalecer as relações com as Unidades Escolares para que os alunos sejam transmissores das informações. Identificar pontos de concentração social como bares, clubes, agremiações, espaços religiosos e posto de saúde, que possam ser usados como centros de distribuição de material de divulgação. Usar meios formais de divulgação como rádio e imprensa escritas de boa penetração nas regiões onde estão inseridas as unidades. O processo de exposição deve ser amplamente divulgado a todos os funcionários, inclusive aos voluntários e pres-

7. PERUZZO, Cicília Krohling. Comunicação e culturas populares. São Paulo: Intercom, 1995. p. 159. 
tadores de serviços que atuam nas áreas de limpeza, vigilância, monitoramento aquático, e técnicos de som e iluminação no teatro. Transformar o usuário no mais representativo elemento difusor das atividades, seja como multiplicador, seja como produtor de material usado para este fim.

\section{Programação das atividades}

Deve haver a disseminação de novas linguagens, de novos conteúdos, mas não necessariamente trabalhar com programação global; deve-se, também, aprofundar os temas que já despertam o interesse em cada região, preocupando-se com a especificidade daquela população.

Fazer levantamento das atividades culturais que já existem, sempre com a participação de membros da comunidade, que poderiam ser levadas para o CEU e, no segundo momento, realizar o intercâmbio dessas atividades entre as unidades. Não só atividades culturais, mas também todas as experiências ocorridas em uma unidade podem ser conhecidas e aproveitadas, ou compartilhadas, por outra. Se um CEU cria um projeto de educação ambiental, este pode ser um modelo para outra unidade; ou na área esportiva, por exemplo, organizar campeonatos entre as unidades. Criar também eventos comuns a todas as unidades, como uma exposição de artesanato com representantes de oficinas de todos os CEUs, num espaço cedido pela Prefeitura.

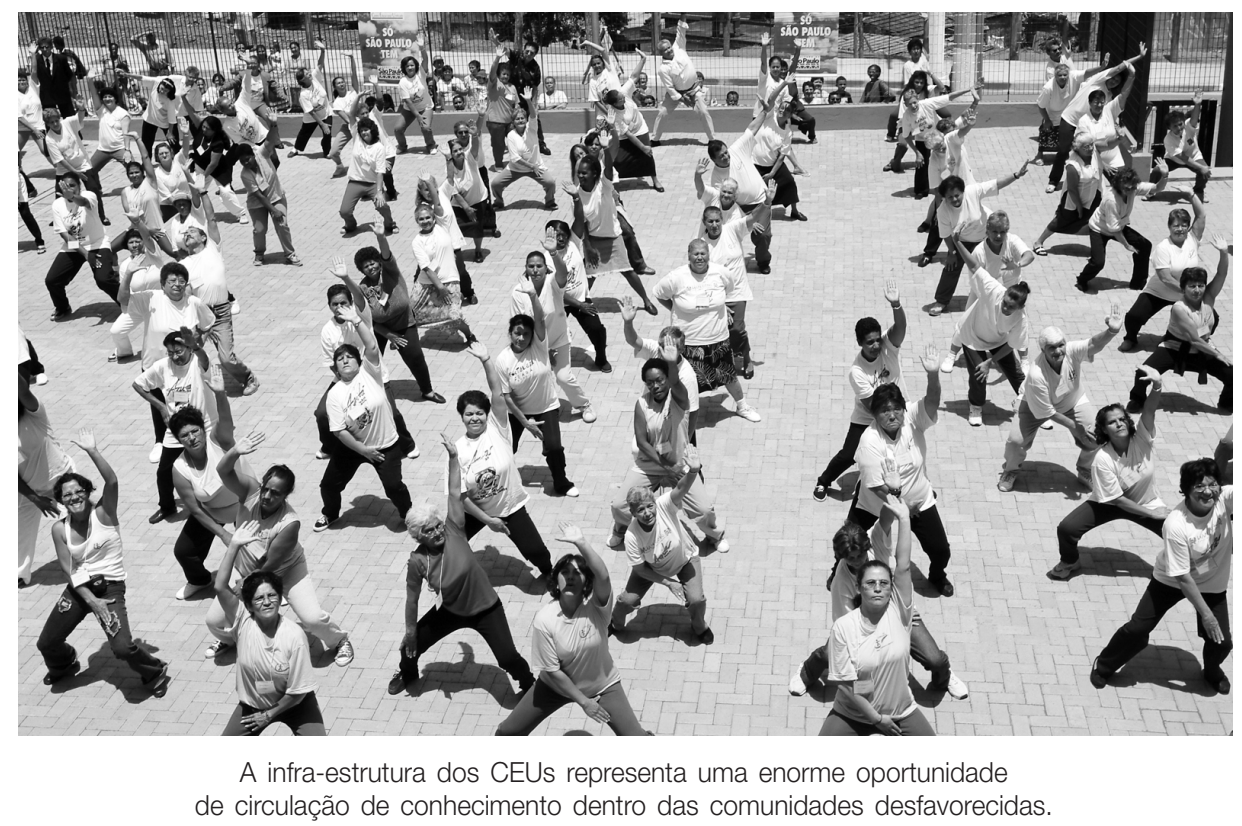

\section{Ferramentas}

A presença de novas tecnologias, como laboratórios de informática, rádio, vídeo e telecentros em cada CEU, demanda a reavaliação do que é conhecimento, sua produção e autoria, para que os equipamentos disponíveis não sejam 
Os CEUS da Prefeitura de São Paulo • Cristiane Hyppolito

subutilizados e cumpram a contento suas relevâncias finais. Neste processo, é importante a consolidação de um canal de comunicação por onde passem, obrigatoriamente, todas as informações acerca das atividades, projetos, parcerias, até mesmo de manutenção predial, nomeações e orçamento; dentro dessa nova diretriz, tais registros seriam uma forma de se ter domínio sobre o conjunto de acontecimentos, programados ou não, que envolvem cada unidade.

A transparência é uma obrigação dos órgãos públicos e um direito dos cidadãos; para tanto, são necessárias a reavaliação e a reestruturação do site para torná-lo um veículo de comunicação dirigido, também, ao público em geral. Da forma como estão colocadas atualmente, as informações não têm abrangência geral, atingindo prioritariamente pessoas ligadas à rede municipal de ensino.

Dentro dos meios tradicionais de divulgação, ações de rotina podem causar efeitos bastante satisfatórios se inseridas nesse contexto de participação efetiva da comunidade. Algumas maneiras de se alcançar isso seriam: elaborar materiais de baixo custo e capacitar a equipe responsável para produzi-lo; criar oficinas específicas para a produção desses materiais; orientar a produção com algumas diretrizes comuns a todos os CEUs; produzir um mailling com usuários dos telecentros para divulgar a programação de todas as unidades; formar redes de troca de informações entre usuários; identificar a existência de rádios comunitárias que possam divulgar as atividades; criar um jornal on-line com colunas de todas as unidades contando novidades, divulgando ações e garantindo espaço para e-mails dos usuários com solicitações, críticas e sugestões; estabelecer um canal direto com a população usuária (caixa de sugestões); usar o apoio das Coordenadorias de Educação para encaminhar aos supervisores de ensino toda a programação dos CEUs, e estes, por sua vez, se encarregariam de divulgá-las em todas as escolas da rede; e utilizar a assessoria de imprensa da Secretaria no sentido de criar um canal de divulgação de serviços junto aos jornais de bairro e rádios.

\section{Canal de informação administrativa}

Criação de um núcleo central de administração de informações, que seja capaz de estabelecer e coordenar o fluxo de comunicação entre todas as unidades e a SME, com atribuições institucionais claras e poder decisório sobre as demais instâncias. Por tratar-se de equipamentos públicos, há que se preservar a transparência das decisões, bem como outras informações relevantes e de interesse da sociedade, assegurando a liberdade de acesso a quem possa interessar.

\section{EDUCOM}

Outro plano que poderia ser integrado aos mecanismos de comunicação seria o Projeto Educomunicação pelas Ondas do Rádio (Educom.rádio), iniciado em 2001 por meio de um contrato entre a Secretaria Municipal de Educação e o NCE - Núcleo de Comunicação e Educação da Escola de Comunicações e Artes da Universidade de São Paulo (ECA-USP) -, e que trabalhou a linguagem radiofônica com professores, alunos e membros da comunidade educativa em 455 escolas de 
ensino fundamental. O Educom, hoje ligado à DOT Ensino Fundamental, ainda mantém rádios em funcionamento nas escolas que possuem os equipamentos.

\section{GESTOR DE COMUNICAÇÃO}

Diante de todas estas propostas, há que se pensar o papel do gestor de comunicação no projeto de intervenção. Como afirma Baccega ${ }^{8}$, é necessário que o gestor não seja um mero reprodutor de técnicas, mas, antes de tudo, um produtor consciente de suas atribuições e de suas responsabilidades dentro da sociedade. É preciso que ele olhe para a comunidade em que vive, entenda suas necessidades e se veja como elemento importante de transformação da realidade.

\section{ESPAÇO PÚBLICO DE EDUCAÇÃO E INCLUSÃO SOCIAL}

A infra-estrutura dos CEUs representa uma enorme oportunidade de circulação de conhecimento dentro das comunidades desfavorecidas onde estão inseridos. Mais do que isso, estão preparados para uma formação qualificada que contemple a convergência de aprendizado e o fortalecimento dos princípios de cidadania; neste sentido, necessitam de processos de comunicação eficientes para que essas novas possibilidades de inclusão possam ser solidificadas.

Resumo: O trabalho apresenta os Centros Educacionais Unificados (CEUs) da Prefeitura de São Paulo, administrados pela Secretaria Municipal de Educação. O enfoque destacado é a comunicação dentro de um espaço público de inclusão social em um ambiente de educação. Procuramos analisar o impacto e as mudanças ocorridas com a introdução desse equipamento em áreas periféricas da cidade, a adaptação e integração da comunidade do entorno e a capacidade de o projeto estabelecer um canal de comunicação entre suas várias instâncias. Buscamos embasamento em outras experiências de utilização de espaços públicos de educação e nas teorias acerca do tema produzidas por educadores e pesquisadores, para, a partir daí, propormos um projeto de intervenção que contemplasse as diferenças entre os núcleos sociais, seus códigos e suas demandas regionais.

Palavras-chave: educação, inclusão social, cidadania, espaço público, gestão da comunicação, Centro Educacional Unificado (CEU).
Abstract: The present work shows the Centros Educacionais Unificados (CEUs) from the town hall of the city of São Paulo, governed by Secretaria Municipal de Educação. The main point is the communication inside a public space of social inclusion in an education atmosphere. We try to analyze the impact and the changes that happened with the introduction of this equipment in the peripheral areas of the city, the adaptation and integration the side community and the capability of the project in establish a communication channel among its various instances. We based our search in other experiences of utilization of public spaces of education and in theories of this theme produced by educators and researchers to, based on this, propose an intervention project that contemplate the differences among social nucleus, is codes and regional demands.

Keywords: education, social inclusion, citizenship, public spaces, communication management, Centro Educacional Unificado (CEU) 